\title{
Zhu, Jianfei. Architecture of Modern China: A Historical Critique. London: Routledge, 2009.
}

\author{
Kevin Lee Pinkoski
}

Jianfei Zhu's book, Architecture of Modern China: A Historical Critique, argues that through social practice, historical conditions and formal evolutions, China has developed an architecture style that is unique from both modern and western styles. Although there are reflections with westernmodernism, new social practices ${ }^{1}$, historical conditions ${ }^{2}$ and formal evolutions ${ }^{3}$ can all be added together to define modern Chinese architecture. Zhu desires to map the development of architecture in China, to support the thesis that Chinese architecture has developed independently with a heavy influence from the rest of the world. This has created a "hybrid of traditions," and therefore special consideration and understanding needs to be taken when examining and creating architecture in China. ${ }^{4}$ As Zhu himself believes, the book will chart points that have yet to be properly mapped, as no work has yet to understand the combination of social movements, political problems and historical developments that create the perspective required to understand architecture in modern China. ${ }^{5}$ This review argues that while Zhu supports his thesis successfully, he downplays the positive influence global architecture styles have had on China. Zhu believes that China currently has grown from specifically Chinese to a hybrid of Chinese and global styles, which points to a trend that will eventual leave Chinese style for a global perspective. Zhu's thesis therefore can only be true if he is writing about an end, a final point in history. Zhu does nothing to either support or deny what impact the history of Chinese architecture will play on the future, what role China will have in the global perspective. This becomes clear after both examining a summary of his work, reviewing his represented sources, and critically analyzing his argument.

Zhu argues his thesis as follows. First, he examines China before and after European influence, depicting how newly introduced scientific developments and rational thinking lead to the development of a new visual culture that combined European linear perspective with Chinese symbolic representation, which, along with cultural and political reforms, created the first evidence of a cross cultural Chinese form. Zhu supports this with the artwork of 18th century artists, Nian Xiyao, Jurui Tu and Baijun $\mathrm{Tu}$, all whom would originally have developed symbolic representation, went on to combine linear perspective with their work. ${ }^{6}$ This created a unique phenomenon of westernization.

Next Zhu elaborates on the establishment of professional architects, developed from artisans as intellectuals. These new professionals collaborate with state authority to create Chinese space with both Chinese and western influences (even while attempting to ignore the west). This is supported by photographic evidence of buildings established during this period, including the Shanghai Municipality Building and the National Central Museum, all government funded projects that combined Chinese traditional design (mainly Chinese roofs and a short cubic design with western ideas surrounding steel and concrete). ${ }^{7}$ Zhu then defines the spatial revolution, the active construction of Chinese architecture created through Soviet and American models, combing both old and new styles with a strict social

\footnotetext{
1 Zhu, Jianfei, Architecture of Modern China: A Historical Critique (London: Routledge, 2009), 5. This includes the development of the role professional architect, his relation to the state, interactions with knowledge, ideological and political stand points.

2 Ibid., 5. This surrounds local and national histories, relations with the west, political developments, and the development of China from being a peripheral country to a key player in modern development.

${ }^{3}$ Ibid., 6. This highlights new concepts of space and form across historical periods, and their influence and interactions with foreign traditions.

${ }^{4}$ Ibid., 9.

5 Ibid., 4.

${ }^{6}$ Ibid., 40.

${ }^{7}$ Ibid., 73.
} 
contract. During this period modernism and critical architecture was not possible, which after 1976 soon became possible. With this transformation the autonomy of the profession developed, allowing architects to localize designs through economic growth and social liberalization, creating what Zhu believes was, "the second modern." West, as individual positions and dialogues began to exist, surrounding both a critical desire and exchange of ideas, causing a geo-global cross-cultural atmosphere. This atmosphere, Zhu believes, was created under the banners a global ethical and political view point, that established a broad, secular, humanistic and ecological ethics, creating an open minded humanism. ${ }^{9}$ Because of this, China was now a global site, which included a merger of Chinese and western perspectives.

A new international political economy allowed for loose restrictions, reform and a relational perspective that emphases power, capital, while still holding true to the Chinese belief of balance and dualism. ${ }^{10}$ Because of this, Zhu believes that China may soon export its design style, creating a loosely restrictive design rules and a relation perspective. ${ }^{11}$ Zhu uses Beijing as a case example, studying the recent three phases in its development that have lead to its current market economy position. Following the city through its state oriented construction under Mao's planned economy, resulting in the establishment of grand historical icons, such as Tianamen Square and the Ten Grand Buildings, to the period of overly urgent foreign investment, creating an invasion on Chinese values, finally resulting in the critical Chinese architecture style, a style encompassing a State-Market and Market-Society relationship, a neither communist nor capitalist design style that believes in heritage and cultural protection in transforming agricultural china into an industrial power. ${ }^{12}$ This new style surrounds modern, mass based, heroic hybrid of all previous design styles. ${ }^{13}$ Although this has established the characteristic Chinese architecture Zhu argues in support of, he also proposes flaws to its formlessness and inadequate urban space. He labels the "Chinese Situation" as an erosion of urban public space, losing its once humane, habitable, accessible quality. ${ }^{14} \mathrm{Zhu}$ believes that the problem lies in a conceived, not lived in urban layout, creating a historical gap between the once accessible and natural formation of cities, to a new, forced development that crosses topographical regions and nature in an unrealistic way. ${ }^{15}$ Zhu finalizes his argument by establishing the sequence and landscape of historical architecture in China, charting how all architecture in China are still influenced by the language and modernism of the state, combined only recently with market and individual influences. Because of this, Zhu believes China had both a unique history, and will be a leader in the hyper modern, large spectrum, neo-liberal architectural future. ${ }^{16}$ These claims are characterized by the sources and examples Zhu uses.

Through examples of Chinese artists and architects, photographic evidence compared to academic presentations and publications by other leading architectural historians, Zhu supports this previous argument. This creates a unique sense of dialogue within Zhu's work, while there is a solidified argument, there is also a chance to both think critically and challenge Zhu's conclusions. This is especially evident when Zhu proposes the lectures of western architects George Baird and Michael Sparks, as compared to Yung Ho Chang and Lui Jaikun, all of whose individual opinions and argument further the spectrum of Chinese/western architectural relations. This open dialogue allows Zhu to make his own presumptions and mediations. The variety Zhu's sources enhance his thesis and beliefs. But as

\footnotetext{
8 Ibid., 103.

9 Ibid., 167.

10 This style of design emphasis symmetry.

11 Zhu believes that this would be represented by a planned space design style, where the entire community and city scape is considered in the construction of each new project.

12 Ibid., 201 and 200.

13 Ibid., 230.

14 Ibid., 240

15 Ibid., 241

${ }^{16}$ Ibid., 243.
} 
for the photographic evidence, how much subjective ability does Zhu have to tell his audiences what they should be recognizing? It would be impossible to critically question with Zhu without having travelled modern China to exploring the historical constructions. Such criticisms would also require an extensive examination of the political dialogue surrounding construction in China. But still, this issue does not serious impede Zhu's ability to support his claims.

Zhu successfully and elaborately argues his thesis. By following the linear development of Chinese history and its relationship to architecture, Zhu proves that Chinese architecture had grown in a unique fashion, outside of, but with influence of global trends. Zhu seems to believe that Chinese architecture was an exemplified part of both modern and historic Chinese culture. He seems to believe it should be a treasured part of this culture, as it managed to develop without assimilation into western practice. For this reason, the book serves as evidence to both the uniqueness and strength of Chinese culture. However, this highlights the faults in Zhu's argument.

The faults in Zhu's argument are as follows. First, Zhu denies crucial benefits and solutions that westernization has offered to China. He states himself that western influence created an enormous pallet of building materials available to the architect, moving away from creatively limited timber. ${ }^{17} \mathrm{He}$ also cannot argue against Michael Speak's position, which claims that although Chinese architecture might not appear western on the outside, it internally "functions exactly like a westernized space." ${ }^{18}$ When Zhu examines the formlessness, or sporadic generation of Chinese cities, he ignores the downfalls in Chinese urban layout, which Henri Lefebvre defines as an overly differentiated, "binear poles" created in conceived space and living space. ${ }^{19}$ Zhu believes the Chinese strive for a balance, but Francois Julien believes that this has created a world that is better to see then to actually live. ${ }^{20}$ Julien supports the idea of planned development of both historical and new spaces, which could lead to a more European combined space. ${ }^{21}$ Zhu does neutralize his biases by presenting these points of view, however, he fails to enter in proper discussion with them. The final issue in Zhu's argument, as pointed out in the introduction, is his inability to understand any possible future developments in Chinese architecture. That is to say, will future trends induce a more dominant western style in the current hybrid development of architecture? Zhu has charted the rise of western influence in his book, but will it not continue to rise, and will China not benefit from this? Zhu himself points out that a global perspective is currently replacing a limited western perspective. ${ }^{22}$ Therefore, Zhu could strengthen his argument by examining what contributions China could make to this global perspective. Zhu supports a historical and cultural protectionism yet he fails to realize this associated himself with the style of restrictions put in place by Mao Zedong, which Yung Ho Chang declares "were so dogmatic and extreme that [they] defeated [their] own purpose in the end. ${ }^{23}$ Although identifying and protecting Chinese developments is important, charting the influence theses developments can play in a global perspective is significant as well. Zhu does manage to present the evidence to create this dialogue, and although he fails to address it himself, he is ignited the possibility for further architecture historians to address these issues, using his own book as a basis and starting point.

Architecture of Modern China: A Historical Critique successfully argues for the uniqueness of Chinese Architecture. While it accurately maps and understands historical developments, it connects Chinese architecture directly to Chinese culture, ignoring the future possibility for a globalization of architecture styles. This is the crucial bias in Zhu's work, as he does not acknowledge the credibility and

\footnotetext{
17 Ibid., 38.

18 Ibid., 152.

${ }^{19}$ Ibid., 216.

${ }^{20}$ Ibid., 218.

21 Ibid., 220.

22 Ibid., 242.

${ }^{23}$ Ibid., 150.
} 
benefit of other architectural styles. However, Zhu's unique combination of sources, and ability to quote sources that counter his own believes neutralizes this bias strengthens his argument. This allows a reader to have an open dialogue with this book, allowing for agreement and disagreement and forcing a reader to create his own resolutions. Therefore, this book as enormous value to other architects and historians, as it establishes a basis on which to understand Chinese development to today, but opens up a multitude of possible discussion on its future. Zhu has established himself as a force on the history Chinese architecture, and the future is open to who ever is willing to challenge his work. 


\section{Bibliography}

Zhu, Jianfei. Architecture of Modern China: A Historical Critique. London: Routledge, 2009. 